\title{
Regional streamflow regimes and hydroclimatology of the United States
}

\author{
Harry F. Lins \\ U. S. Geological Survey, Reston, Virginia
}

\begin{abstract}
The dominant regions of interannual streamflow variability in the United States are defined, and their seasonality and persistence characteristics identified, using an orthogonally rotated principal components analysis (RPCA) of a climatically sensitive network of 559 stream gages for the period 1941-1988. This classification of streamflow regimes is comprehensive and unique in that separate analyses of the streamflow record, for each month of the year, are carried out to detail the month-to-month changes in the dominant streamflow patterns. Streamflow variations, or anomalies, in the Upper Mississippi, South Atlantic/Gulf, Far West, Ohio Valley, Northeast, and Eastern/MidAtlantic regions, as well as a pattern of opposing streamflow anomalies in the West, are observed in all seasons of the year. Anomalies in the Southern Plains and New England regions are observed in autumn, winter, and spring; those in the Rocky Mountains and Middle Mississippi regions occur in late spring and summer.
\end{abstract}

\section{Introduction}

The behavior of low-frequency (monthly to seasonal) regional-scale variations in streamflow is of considerable interest to hydrologists and water-resource managers. In recent years, for example, there has been a dramatic increase in the number of investigations focused on the hydrologic and waterresources consequences of climatic variability and change. Many of these studies have been primarily concerned with the identification of potentially adverse effects [e.g., Gleick, 1987]. Others have sought to develop improved methods for evaluating the relations between observed and modeled climatic variations/changes and streamflow [Hay et al., 1992]. Without regard to the specific orientation of these various investigations, all could benefit from a comprehensive evaluation and classification of the low-frequency patterns and temporal behavior of regional streamflow across the United States. With such information a solid basis would be established for understanding better the relations between regional streamflow and variations in the general circulation of the atmosphere on a monthly to seasonal basis.

The purpose of this paper is to develop a hydroclimatology of streamflow for the United States, a hydroclimatology that defines the dominant regions of streamflow variability and their seasonality and month-to-month persistence and that explains these spatial and temporal patterns in terms of their congruence with recurrent atmospheric and oceanic conditions. Orthogonally rotated principal components analysis (RPCA) of mean discharge for each of the 12 calendar months is used to identify and describe the seasonality and persistence of the major modes of interannual variability.

\section{Data}

Monthly mean values of streamflow (discharge) for the 48year period 1941-1988 were assembled from 559 gaging stations across the conterminous United States (Figure 1). A year

This paper is not subject to U.S. copyright. Published in 1997 by the American Geophysical Union.

Paper number 97WR00615. in this context (and as used throughout this report) is defined as a water year, which is the 12-month period beginning on October 1 and continuing through September 30 and is designated by the calendar year in which it ends. Accordingly, water year 1941 began on October 1, 1940, and ended on September 30, 1941. These streamflow records represent a subset of the U.S. Geological Survey's (USGS) Hydro-Climatic Data Network (HCDN) [Slack and Landwehr, 1992; Slack et al., 1993]. The HCDN consists of 1659 sites throughout the United States and its territories and contains a total of 73,231 water years of daily mean discharge values. This collection of observations was developed specifically to provide a national hydrologic data set sensitive to the effects of climatic variability, that is, free of such human influences as regulation or diversion of the watercourse, nonstandard measurement or recording practices, or changes in measurement procedures. The 1659 stations were screened to obtain a sample that was both long (over 40 years of continuous coverage to the end of the HCDN record, i.e., 1988) and spatially diverse. A total of $256 \mathrm{HCDN}$ stream gages had continuous records from 1930 to 1988, while 716 had continuous records from 1950 to 1988 . The largest increase in the number of gages having continuous records through 1988 occurred between 1939 and 1941, when there was a $16 \%$ increase, from 468 to 559 . This increase also significantly improved the geographic distribution of coverage, especially in the Central and Rocky Mountain states. On this basis the decision was made to begin the record in 1941 with 559 stations.

Six criteria were used to evaluate whether station records were acceptable for inclusion in the HCDN: (1) Data had to be available in electronic form. (2) Records from any station, whether currently active or not, for any water year through 1988 were considered to ensure the broadest possible geographic and temporal coverage. (3) A record length of at least 20 water years was preferred, but shorter records that were otherwise acceptable were used, especially those in areas of underrepresented coverage. (4) The predominant accuracy rating assigned by the USGS district office had to be at least "good" for the record of daily mean discharges in those water 


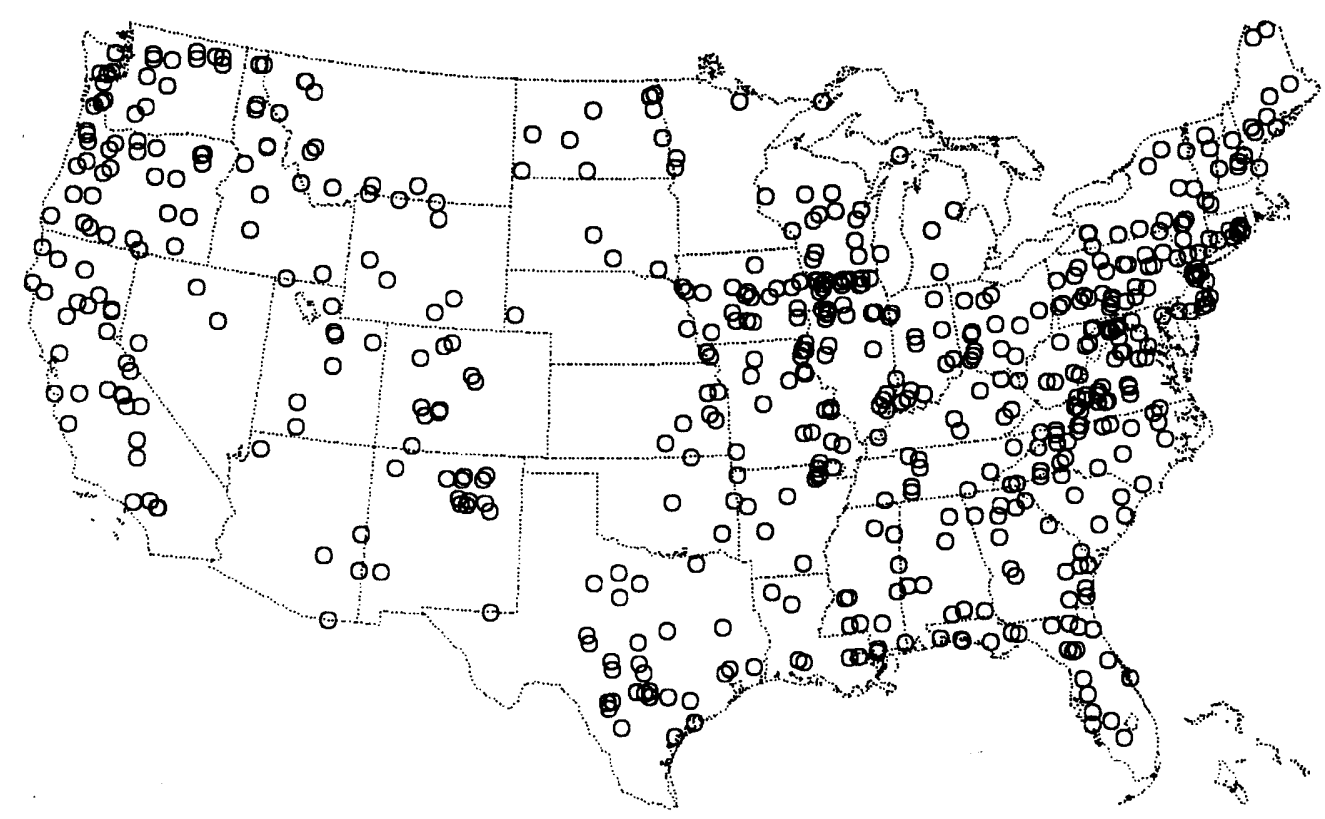

Figure 1. Distribution of the 559 stream gages from which monthly mean discharge values were used in the rotated principal components analysis.

years chosen. (5) The records should reflect unimpaired basin conditions; that is, there should be no overt adjustment of "natural" streamflow, such as flow diversion or augmentation, regulation by a containment structure, or reduction of base flow by extreme groundwater pumping; nor should the degree of human activities in a basin (such as land use changes) be sufficient to affect the value of monthly mean discharge. (6) The discharge data reported in the records must have been obtained by means of standard USGS measurement practices. The last two criteria ensure that any trends detected in the records are due to actual changes in streamflow rather than to human activities or changes in measurement methods.

Although in any collection of stream-gage records a variety of frequency distributions will be identified, the data are typically best approximated by the lognormal distribution. More specifically, research focused on flood frequency estimation has demonstrated that the only distributions that are largely unbiased estimators are the lognormal and the log-Pearson III [Beard, 1974]. As a result, logarithmic transformations of discharge data are typically performed by investigators undertaking statistical analyses that assume normally distributed data. Although the application of principal components analysis (to be performed in this study) requires no distributional assumptions about the data, the tests for component statistical significance are based on a multivariate normal distribution [Preisendorfer et al., 1981]. Inspection of the frequency distributions (histograms) of the data from several dozen gaging stations indicated a tendency toward the lognormal distribution. However, a more comprehensive evaluation of the distributional characteristics of the HCDN database, conducted by Thomas and Olson [1992], confirmed that the constituent monthly mean stream-gage records are most appropriately fit by the lognormal distribution. Thus the monthly mean streamflow values were logarithmically transformed prior to analysis.

\section{Methods}

The dominant patterns, or modes, of spatial variability in U.S. streamflow are represented as the principal components of a correlation matrix. As a technique for isolating coherent regional patterns in large multivariate geophysical and geochemical data fields, principal components analysis (PCA) has found considerable use. Its application to long-term $(\geq 30$ years) records of streamflow on a continental scale is a natural extension of its successful use in delineating regional patterns in precipitation [Walsh and Mostek, 1980; Richman and Lamb, 1985], temperature [Karl et al., 1982], sea level pressure [Brinkmann, 1981], atmospheric circulation [Horel, 1981, 1984; Barnston and Livezey, 1987], drought [Karl and Koscielny, 1982], and cyclone frequency [Hayden, 1981]. Although PCA has been used extensively in the hydrologic and hydrochemical sciences, its application has been primarily oriented toward the grouping of multiple variables (as in water-quality studies, for example) as opposed to defining regional behavior in a single variable. The most notable exceptions to this are several analyses of annual streamflow variations [Bartlein, 1982; Lins, 1985a, b], an assessment of monthly outflow (i.e., the ratio of accumulated station daily streamflow to drainage area above the station) from the continental United States [Guetter and Georgakakos, 1993], and a study of sulfate variability in pristine streams [Lins, 1986].

In this study, principal components are calculated using correlation rather than covariance matrices to eliminate any tendency for skewed or overweighted spatial patterns resulting from point or regional differences in variance magnitude. For example, the streamflow data set contains records from river basins of widely varying sizes. Some rivers have monthly mean discharges of only a few cubic meters per second, while others have flows of hundreds to thousands of cubic meters per second. Use of the correlation matrix, in effect, standardizes the variations at each sample point. Thus the figures describing streamflow patterns represent "anomalies," or variations from the mean state, because the principal components are computed from the correlation coefficients. The mapped values are scaled to be correlations between the original discharge at a given location and the time series of the principal component in question. Another characteristic associated with the use of 
the correlation matrix is that the signs of the pattern core areas, or "centers," are arbitrary. That is, the polarity of a pattern is interpretable both as shown or in reverse.

To produce physically meaningful, distinct, and statistically robust solutions, the vectors derived from the PCAs are orthogonally rotated using the varimax criterion. An exhaustive evaluation of the efficacy, stability, and robustness of orthogonally rotated principal component analysis (RPCA), particularly as applied to atmospheric circulation data, is presented by Barnston and Livezey [1987]. The extension of RPCA to streamflow is made in this study because streamflow shares certain properties with atmospheric circulation, and Barnston and Livezey's analysis confirms the appropriateness of applying the technique to the latter, where these properties are present. The properties are (1) the regionality displayed in lowfrequency variability and (2) the fact that the regions may not be spatially orthogonal to each other, but appear to be temporally uncorrelated [Barnston and Livezey, 1987].

To ensure that the best possible identification and description of the seasonality and persistence of the major patterns of variability in streamflow were obtained, the RPCA was performed on data organized by individual months of the year. That is, 12 separate data files, one for each month of the year, were constructed for each variable. An RPCA was then done on the October streamflow data, the November streamflow data, etc., until 12 RPCAs were completed. The streamflow data matrices were each dimensioned $48 \times 559$, that is, 48 years of values (water years 1941-1988) for a given month, measured at 559 stream gages. It is worth noting that in the years prior to the advent of digital computers, some researchers raised questions about PCA solutions when the number of variables is larger than the number of cases. The issue is the constraint imposed on the dimensionality of the dispersion matrix where the number of eigenmodes would be less than the number of original variables. The concern was that this condition might perturb the characteristics of the solution. Importantly, the literature provides no insight on the effects of an $n<p$ data matrix on PCA solutions. However, the author previously investigated this issue using other data sets where $n<p$ by performing PCA successively on the data matrix and then its transpose. The loadings pattern of the former was then evaluated in terms of the scores of the latter. In all cases the scores of the components for the transposed matrix presented a pattern consistent with what one would expect in the loadings of the original matrix. Thus it appears that the $n<p$ condition does not perturb the characteristics of the overall PCA solution and, most particularly, the characteristics of the lowerorder eigenmodes.

Only the first 10 principal components resulting from each of the 12 analyses were orthogonally rotated. The decision to rotate 10 components was based on the application of an objective selection procedure, rule $\mathrm{N}$, that indicated that rotation of the first 10 components was not likely to result in the retention of insignificant (either physically or statistically) modes of variability [Preisendorfer and Barnett, 1977]. The rule, developed in a series of Monte Carlo experiments, is designed to determine if the eigenvalues, or percentages of variance, calculated in a principal components analysis (unrotated solution) of a geophysical data set (in this case streamflow observations) are distinguishable from those produced from a spatially and temporally uncorrelated random process. This particular test was applied in lieu of several other dominant variance selection rules because it (1) consistently exhibits the lowest variance in rule performance and (2) represents a basically conservative test but is less likely than others to omit potentially useful information [Preisendorfer et al., 1981; Preisendorfer, 1988]. As the rule is applied, the statistical significance of a principal component is suspect when its corresponding geophysical eigenvalue is less than that generated from a set of random data.

The application of rule $\mathrm{N}$ in the present study is considered inexact because it is based on interpolating and extrapolating random data eigenvalues from a published table [Overland and Preisendorfer, 1982] rather than developing random data eigenvalues by conducting an independent Monte Carlo simulation. This is considered appropriate since a careful review of Overland and Preisendorfer's [1982] Table 1 clearly indicates that for matrices with large numbers of observations and/or variables, the eigenvalue (percentage of variance) changes between successive PC modes are very small. Additionally, the percentage of variance explained for the first to fifth random data eigenmodes interpolated from their table for an $n \times p$ matrix with dimensions $50 \times 500$ (which is slightly smaller than the $48 \times 559$ streamflow matrix and is therefore a conservative comparative case) varies from $4.18 \%$ to $3.47 \%$. These percentages fall within the range of values that typically appear for eigenmodes 6 through 10 of the streamflow data.

As an example, the variances explained by the interpolated random data PCs for modes 1 to 5 are compared to those for the first 10 unrotated PCs for April streamflow in Table 1. What appears most clearly in the table is that the variances explained by the first five PCs of streamflow are all much larger than their respective values for the first five random data PCs (meaning that they pass the rule $\mathrm{N}$ significance test). If the variances explained for the random data PCs are then extrapolated downward as a negative exponential to estimate values for modes 6-10, the variances explained by streamflow PCs 6-9 also exceed the value of their random data counterparts, while that for PC 10 is only slightly less. Thus, on the basis of these comparisons, the decision to rotate 10 principal components is considered sound and not likely to produce spurious, insignificant, or unrealistic patterns.

The RPCA loading patterns contain a relatively large number of near-zero values (i.e., between +0.20 and -0.20 ) and a comparatively small number of high positive or negative values (i.e., $>+0.80$ or $<-0.80$ ). In other words, the patterns have

Table 1. Comparison of the Percentages of Variance Explained by the First 10 Unrotated Principal Components of Streamflow in April With the First 10 Unrotated Principal Components of a Set of Random Variables

\begin{tabular}{ccc}
\hline PC Mode & $\begin{array}{c}\text { April Streamflow } \\
\text { Variance Explained }\end{array}$ & $\begin{array}{c}\text { Random Data } \\
\text { Variance Explained }\end{array}$ \\
\hline 1 & 20.78 & 4.18 \\
2 & 11.28 & 3.88 \\
3 & 8.18 & 3.74 \\
4 & 6.01 & 3.59 \\
5 & 5.46 & 3.47 \\
6 & 4.56 & $3.33^{*}$ \\
7 & 3.72 & $3.19^{*}$ \\
8 & 3.27 & $3.05^{*}$ \\
9 & 2.93 & $2.92^{*}$ \\
10 & 2.58 & $2.79^{*}$
\end{tabular}

*Value interpolated from Table 1 of Overland and Preisendorfer (1982). 
distinct regional foci or centers. This is consistent with the results of other studies where rotated principal components are used and with the theoretical basis behind component rotation [Richman, 1986; Thurstone, 1947]. Comparison of the loadings for the rotated PCs with those for the unrotated components revealed that the gages having the highest unrotated loadings for a given PC pattern were virtually identical to their rotated counterparts in all cases. The primary difference was that the magnitude of the loadings for the rotated cases increased by several hundredths to occasionally a tenth of a point (generally $0.03-0.10$ ). In fundamental terms therefore the orthogonal rotation served only to refine the patterns extant within the unrotated solution. The rotation did not change the spatial pattern in any component in any month.

A note on principal components analysis, as applied in this study, is necessary. Buell [1971] pointed out that the values of many meteorological variables are naturally continuously distributed but that the discrete formalism of PCA could produce patterns that misrepresent these continuous fields. Karl et al. [1982] built on this work by demonstrating that the loading patterns produced by performing a PCA on irregularly spaced data were distorted due to overestimation of loading values in areas of dense sampling. They then describe how the problem can be avoided by interpolating the irregularly spaced data to a grid which closely approximates equal area.

The distribution of the 559 stream gages used herein is not uniform, so one may question the accuracy or representativeness of the streamflow PCA. In considering this question it is important to recognize that unlike a relatively smooth and continuously varying field, such as an atmospheric pressure surface, streamflow is measured as a spatially discrete variable, strongly influenced by the physical and biological characteristics of the drainage basin in which it occurs. The discrete nature of streamflow may mean that it is better adapted to the discrete formalism of PCA than to, say, atmospheric circulation or sea-surface temperature. Moreover, the alternative to performing a PCA on irregularly spaced streamflow data, that is, to average or somehow otherwise grid the gage records, is conceivably far more likely to produce errors or distortions. Clearly, for any reasonably sized grid cell array appropriate for nationwide analysis of streamflow variability, the individual grid cells would have to be large enough to encompass a wide variety of drainage basins having, in many cases, significantly different physical and biological characteristics. The representativeness and accuracy of gridded hydrologic data have yet to be systematically studied. Perhaps with advances in macroscale hydrologic modeling and improved hydrologic representations in general circulation models, such questions of representativeness will be addressed.

As a final point, Lins [1985b] considered the issue of sample point distribution in his principal components analysis of annual streamflow data. He performed a spatial sensitivity analysis of the PC patterns by reducing the sample size and recalculating the principal components. Lins concluded that, at least for the primary modes of variability, the patterns were fundamentally stable.

In light of these considerations, it was felt that performing an RPCA on a spatially irregular distribution of streamflow data was no more likely to produce distorted or erroneous patterns than a similar analysis on a gridded field of streamflow data. Thus RPCA was applied to the streamflow data compiled for the stream gages depicted in Figure 1. Additional com- ments explaining and justifying this approach appear at the end of the following section.

\section{Results}

Eleven distinct and independent regional streamflow regimes in the United States are identified using RPCA. Some of these regimes are consistent with regional patterns previously described in the literature at both seasonal and annual time frames. Several, however, are described for the first time in this study. Only those patterns appearing in at least three consecutive, or nearly consecutive, calendar months were defined as independent regimes. Regional designations were assigned by subjective identification of the geographic area enclosed by the 0.60 principal component loading contour. Throughout the following discussion, "mode" is used interchangeably with "pattern." This is consistent with the convention used by climatologists and oceanographers in describing the principal components of spatially distributed atmospheric and oceanographic data.

The following regional patterns are depicted in maps that illustrate their characteristic forms (Figures 2-12). Examples of each pattern as they appear in 2 months of the year are provided, although some patterns occur in all 12 calendar months. (A complete set of pattern maps, for all regions and months of occurrence, is available from the author.)

\section{Upper Mississippi Pattern (UM)}

The Upper Mississippi pattern (Figure 2) is distinct in all 12 months. Although the regime undergoes some changes in shape throughout the year, it maintains a relatively strong and stable core centered on the border area of Iowa, Wisconsin, and Illinois. The pattern expands northeastward and southward from the core during the autumn months to include much of Michigan and Missouri. At this time, UM is the dominant region of streamflow variability across the United States, explaining $12-14 \%$ of the total variance in U.S. streamflow (mode numbers 1 or 2; Table 2). It then contracts to a very stable, although less dominant, pattern, centered on eastern Iowa, that persists from February through June. It reaches its minimum extent in July and August.

An interesting aspect of this pattern occurs during April, May, and June, when a weaker center of opposite sign appears in Texas. Such a regional opposition in streamflow anomalies has been observed by a number of investigators [Busby, 1963; Nace and Pluhowski, 1965; Lins, 1985a], although it has never been explained in terms of synoptic climatology. It appears that this is because the opposition does not occur in conjunction with a single climatic pattern. In the case where there are low flows in the Upper Mississippi coincident with high flows in the Southern Plains, for example, high pressure centered over the Great Basin, the Northern Rockies, or even the Great Lakes has given rise to the pattern [Namias, 1979]. In the opposite case, low pressure centered over the Ohio Valley or over the Northern Plains has been responsible. Notably, this opposition occurs during the three months of the year when the Upper Mississippi region experiences its highest median monthly flows.

\section{Eastern/Mid-Atlantic Pattern (EMA)}

Another all-season pattern is the Eastern/Mid-Atlantic (Figure 3), which has a strong center over Virginia. The prototype for this pattern appears in January, one of 5 months when the 
Upper Mississippi Pattern-December (Mode 2, 14.5\%)

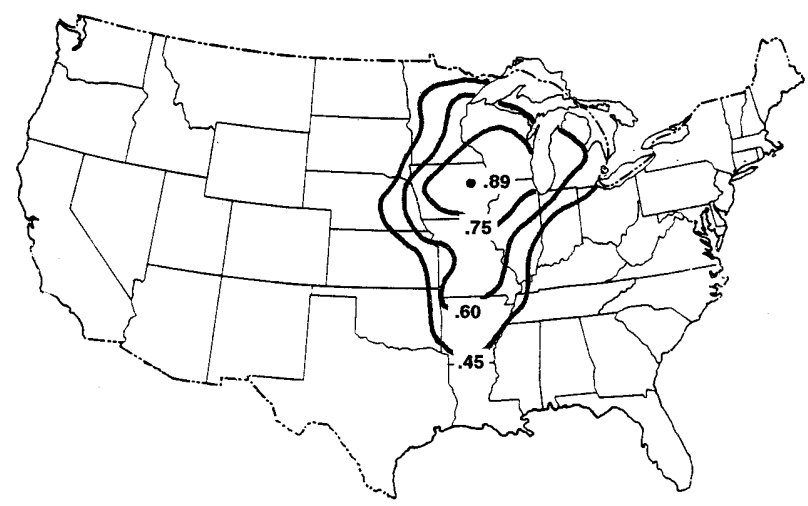

Upper Mississippi Pattern -- June (Mode 3, 8.7\%)

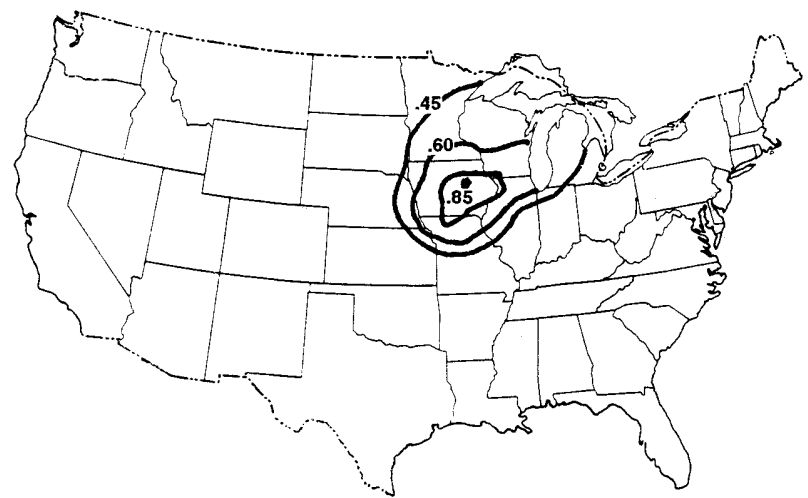

Figure 2. The Upper Mississippi (UM) pattern of streamflow variability in December (top; mode 2) and June (bottom; mode 3 ). Contoured values are principal component loadings; contour interval is 0.15 .

EMA appears as mode 1 (Table 2). The pattern is most intense in December and January and weakest in June (mode 6) and July (mode 5), which generally conforms with the seasonal pattern of mid-Atlantic storm frequency [Dolan et al., 1988]. The EMA does not appear in November or August. From a moderately strong form in September and October, it expands
Eastern/Mid-Atlantic Pattern - January (Mode 1, 16.7\%)

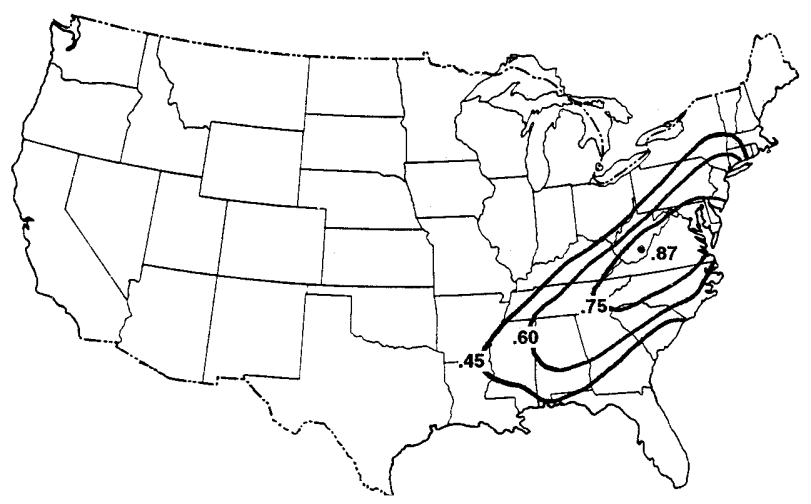

Eastem/Mid-Atlantic Pattern -- April (Mode 1, 15.5\%)

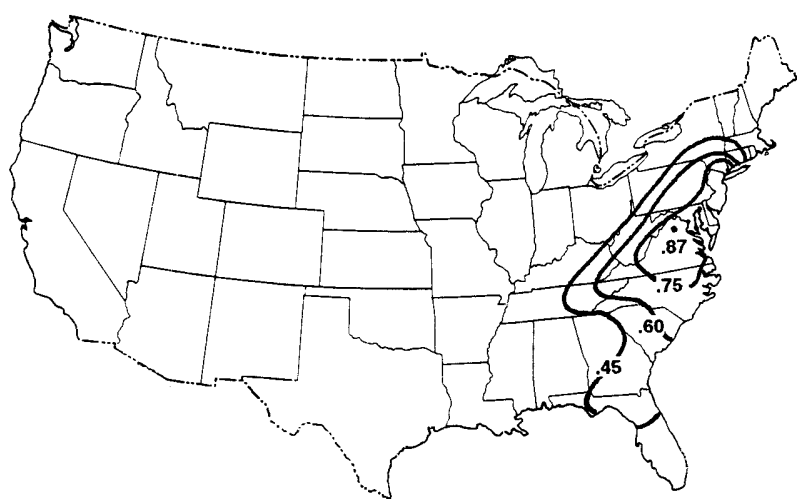

Figure 3. The Eastern/Mid-Atlantic (EMA) pattern of streamflow variability in January (top; mode 1) and April (bottom; mode 1). Contoured values are principal component loadings; contour interval is 0.15 .

and elongates to its maximum extent in December and January, and then contracts somewhat during the late winter months. In April the pattern intensifies both northward and southward along the coast and thereafter undergoes a gradual contraction to a very weak pattern in July.

Although month-to-month variations in the strength of this

Table 2. Mode Numbers of, and the Percentages of Variance Explained By, Patterns Defined by the Rotated Principal Components of Mean Monthly Streamflow, by Individual Months

\begin{tabular}{|c|c|c|c|c|c|c|c|c|c|c|c|}
\hline \multirow[b]{2}{*}{ Month } & \multicolumn{7}{|c|}{ All Seasons } & \multicolumn{2}{|c|}{ Cold } & \multicolumn{2}{|c|}{ Warm } \\
\hline & $\mathrm{UM}$ & SAG & FW & OV & WO & $\mathrm{NE}$ & EMA & SP & NEW & RM & MM \\
\hline Oct. & $1(12.65)$ & $4(7.47)$ & $7(5.64)$ & $6(5.84)$ & $5(7.14)$ & $2(9.78)$ & $3(7.90)$ & $8(5.52)$ & 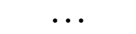 & $\ldots$ & $\ldots$ \\
\hline Nov. & $1(13.64)$ & $2(11.19)$ & $6(6.35)$ & $5(6.69)$ & $4(7.00)$ & $3(9.35)$ & $\cdots$ & $7(4.83)$ & $9(3.46)$ & $\cdots$ & $\cdots$ \\
\hline Dec. & $2(14.46)$ & $5(6.29)$ & $4(7.06)$ & $\cdots$ & $6(5.95)$ & $3(7.79)$ & $1(16.14)$ & $7(4.86)$ & $9(3.36)$ & $\cdots$ & $\cdots$ \\
\hline Jan. & $3(10.62)$ & $7(4.47)$ & $4(7.60)$ & $2(12.49)$ & $8(4.32)$ & $\ldots$ & $1(16.65)$ & $5(5.82)$ & $6(4.62)$ & $\cdots$ & $\ldots$ \\
\hline Feb. & $5(8.00)$ & $7(5.15)$ & $6(5.47)$ & $1(11.88)$ & $4(8.15)$ & $3(9.50)$ & $2(11.83)$ & $8(4.92)$ & $\cdots$ & $\cdots$ & $\cdots$ \\
\hline March & 1 (10.97) & $7(5.51)$ & $2(10.57)$ & $4(10.49)$ & $8(4.51)$ & $5(6.43)$ & $3(10.57)$ & $6(5.80)$ & $\ldots$ & $\ldots$ & $\ldots$ \\
\hline April & $3(8.56)$ & $5(6.76)$ & $7(5.26)$ & $4(7.62)$ & $\cdots$ & $8(4.14)$ & $1(15.54)$ & $6(6.42)$ & $10(3.44)$ & $2(9.15)$ & $\cdots$ \\
\hline May & $2(8.85)$ & $4(7.38)$ & $6(6.79)$ & $3(8.26)$ & $7(6.20)$ & $5(6.87)$ & $1(10.61)$ & $\ldots$ & $\ldots$ & $8(5.14)$ & $\ldots$ \\
\hline June & $3(8.68)$ & $4(6.98)$ & $5(6.65)$ & $7(5.76)$ & $1(9.50)$ & $2(9.26)$ & $6(6.00)$ & $\cdots$ & $\ldots$ & $9(4.11)$ & $8(5.63)$ \\
\hline July & $7(6.49)$ & $6(6.85)$ & $3(7.90)$ & $4(7.42)$ & $2(8.28)$ & $1(8.34)$ & $5(7.20)$ & $\cdots$ & $\cdots$ & $8(4.49)$ & $\cdots$ \\
\hline Aug. & $4(7.39)$ & $2(8.04)$ & $5(7.15)$ & $6(6.18)$ & $3(7.58)$ & $1(8.05)$ & $\ldots$ & $\cdots$ & $9(3.75)$ & $\ldots$ & $7(5.04)$ \\
\hline Sept. & $2(7.94)$ & $6(6.09)$ & $5(6.81)$ & $4(7.16)$ & $7(5.67)$ & $3(7.33)$ & $1(8.40)$ & $10(3.52)$ & $\cdots$ & $9(3.61)$ & $8(5.42)$ \\
\hline
\end{tabular}

See text for explanation of pattern abbreviations. Percentages of variance are given in parentheses. 
Northeast Pattem - October (Mode 2, 9.8\%)

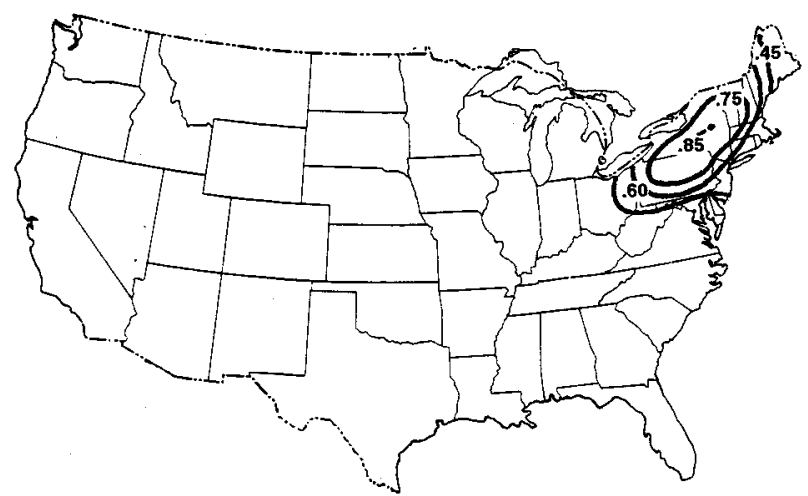

Northeast Pattem -- June (Mode 2, 9.3\%)

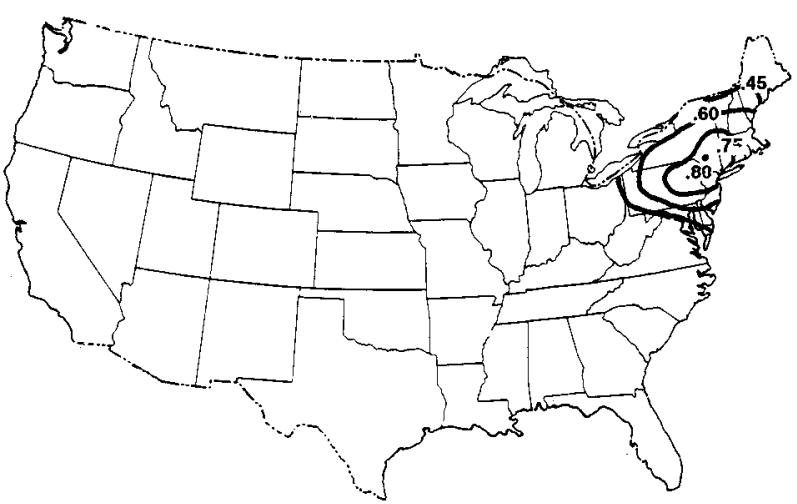

Figure 4. The Northeast (NE) pattern of streamflow variability in October (top; mode 2) and June (bottom; mode 2). Contoured values are principal component loadings; contour interval is 0.15 .

pattern are evident, it maintains a characteristic southwest-tonortheast elongated shape in all 10 months that it appears. Most certainly, this configuration is influenced by the northeastward trending tracks of extratropical cyclones that form over the southeastern United States and adjacent Gulf and Atlantic coastal waters [Zishka and Smith, 1980; Hayden, 1981; Whittaker and Horn, 1984]. The 5 months of greatest pattern extent, from December through April, coincide exactly with the 5 months of maximum storm frequency along the midAtlantic coast [Dolan et al., 1988]. Moreover, the very contracted patterns appearing in June and July occur coincident with the two months of minimum mid-Atlantic storm frequency.

\section{Northeast Pattern (NE)}

The Northeast pattern is clearly evident in all months except January (Figure 4; Table 2). Although less pronounced than in the EMA pattern, the NE also has a northeastward trending elongation as well as a strong coastal association. As a regional mode of streamflow variability, $\mathrm{NE}$ is most dominant during the summer and autumn months. It appears as mode 1 during July and August and is never weaker than mode 3 from May through December. Throughout this period the NE center, while shifting from as far south as New Jersey (August and
Ohio Valley Pattern -- January (mode 2, 12.5\%)

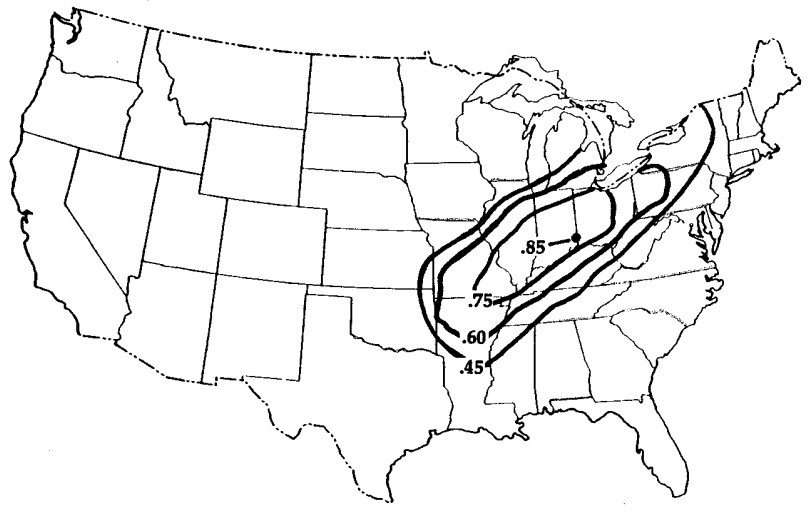

Ohio Valley Pattern -- May (mode 3, 8.3\%)

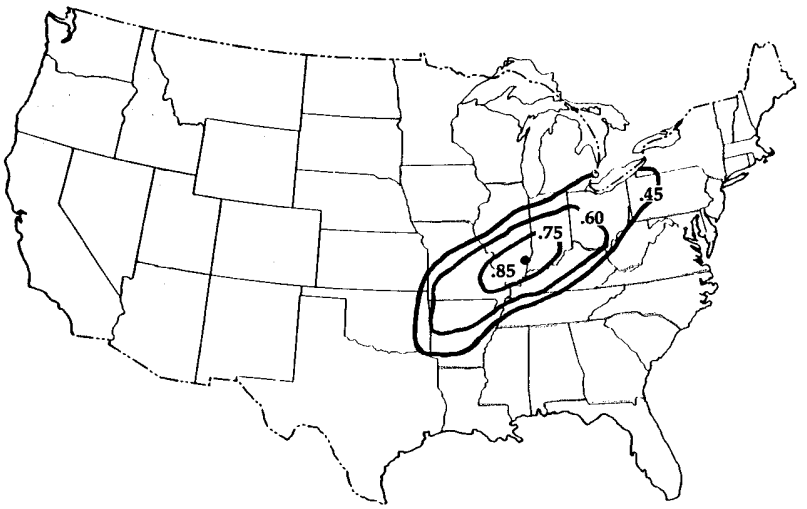

Figure 5. The Ohio Valley $(\mathrm{OV})$ pattern of streamflow variability in January (top; mode 2) and May (bottom; mode 3). Contoured values are principal component loadings; contour interval is 0.15 .

November) to as far north as New Hampshire and Maine (October and February), reflects an unambiguous Atlantic coastal influence. Primary and secondary storm tracks for July, October, and January most directly affecting the NE region are all directed northeastward along the U.S. eastern seaboard or northward from Cape Hatteras through eastern New York [Whittaker and Horn, 1984].

In contrast, when the pattern is weakest, in March (mode 5) and April (mode 8), it exhibits a distinct east-west alignment stretching across the Great Lakes. This change in configuration during the spring season is consistent with the appearance of a more eastward moving primary storm track that reaches from the Great Basin, across the southern Great Lakes, and into the Atlantic passing south of Newfoundland [Whittaker and Horn, 1984]. It also occurs in phase with a secondary storm track that begins in Northern Alberta and moves southeastward across the NE region.

\section{Ohio Valley Pattern (OV)}

A fourth pattern appearing in all seasons centers on the Ohio Valley (Figure 5). The core of the OV pattern encompasses the border area of Indiana, Ohio, and Kentucky, in good agreement with the Ohio water resource region as defined by the U.S. Water Resources Council [1970]. The OV pattern achieves its greatest intensity in winter, appearing as mode 2 in 
January and mode 1 in February (the pattern prototype), when it explains approximately $12 \%$ of the total variance in U.S. streamflow.

The pattern exhibits considerable geographic stability from January through May with a southwest-to-northeast elongated form that has close contemporaneous spatial complementarity with the EMA pattern but without overlap. This suggests that the two patterns are controlled by different cyclonic and anticyclonic tracks. Whereas EMA is dominated by the U.S. east coast cyclone track, OV appears coincident with primary North American tracks that originate in the Great Basin-Colorado cyclogenetic areas and extend northeastward and eastnortheastward to the Great Lakes and to southern New England [Whittaker and Horn, 1984].

The pattern is weakest in June (mode 7) and September (mode 4), when it appears in a bimodal configuration with centers in Ohio and Mississippi. This form of the OV pattern seems to be associated with periods of widespread, but often localized, flooding over much of the eastern United States, as occurred in June of 1946, 1947, 1973, and 1974 and in September of 1950, 1979, and 1981 [Holmes, 1987]. On the dry side, it more frequently occurs in conjunction with very broad areas of drought, such as occurred in June of 1966 and 1977 and in September of 1953 and 1966 [Holmes, 1987].

\section{South Atlantic/Gulf (SAG)}

A second 12-month pattern is the South Atlantic/Gulf (Figure 6; Table 2). Although very persistent, the SAG regime is generally less dominant than the previously discussed patterns. It is strongest in November and August, when it appears as mode 2. Throughout the rest of the year, however, it varies from mode 4 to mode 7. Median streamflows in the SAG region are highest from January to April and are both lower and more stable from May until December. The pattern exhibits a seasonal shift between two configurations, an elongated winter form and a more diffuse summer form.

A pronounced northeastward elongation develops during the cold season, when the surrounding atmosphere becomes more baroclinic and cyclogenesis is more prevalent in the Gulf of Mexico, with storms tracking north and east across northern Florida [Hayden, 1981]. As the cold season progresses, the core of the SAG pattern shifts southeastward, presumably in conjunction with a southward shift in the mean position of the air mass frontal boundary and associated frontal cyclone track. By March, as the cold air masses begin abating, the core area recedes northward. During the warm season, as the atmosphere becomes more barotrophic, streamflow is influenced more by convective precipitation (often associated with fronts) than by well-defined families of cyclones.

\section{Western Opposition Pattern (WO)}

One of the best documented modes of streamflow variability is the Western Opposition (Figure 7), a pattern characterized by streamflow anomalies of one sign in the Pacific Northwest coincident with anomalies that are weaker but of opposite sign in the Southwest. Reference to this pattern has been made by Nace and Pluhowski [1965], Langbein and Slack [1982], Meko and Stockton [1984], Lins [1985a, b], Cayan and Peterson [1989], and Redmond and Koch [1991]. On the basis of the strength of the loadings mapped in Figure 7, this pattern could legitimately be termed the Pacific Northwest pattern. In each of the 11 months in which WO appears, the highest loadings occur in the Pacific Northwest. However, in the months when
South Atlantic/Gulf Pattern -- November (mode 2, 11.2\%)

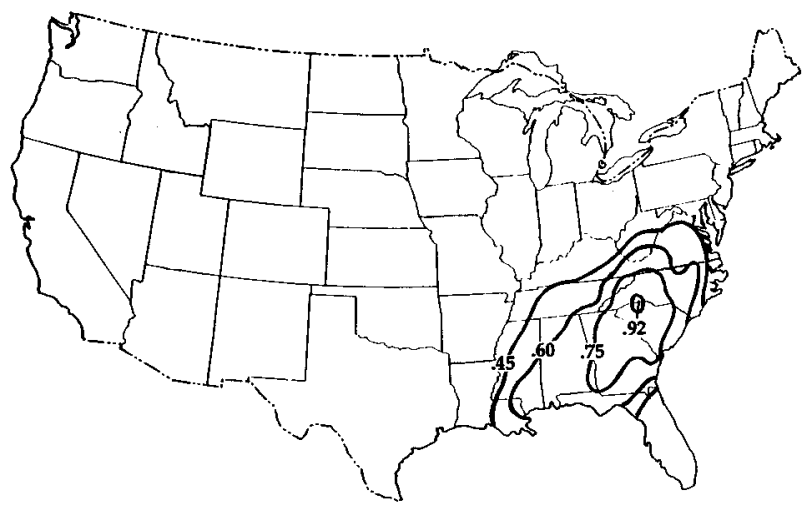

South Atlantic/Gulf Pattem -- August (mode 2, 8.0\%)

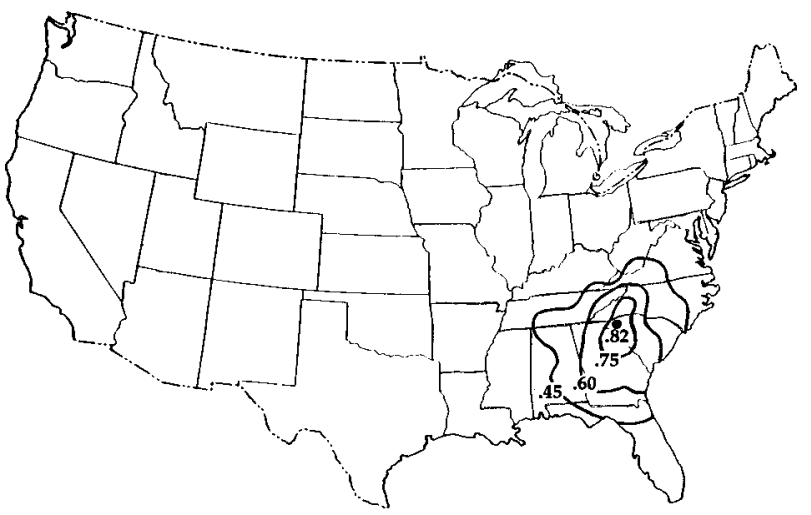

Figure 6. The South Atlantic/Gulf (SAG) pattern of streamflow variability in November (top; mode 2) and August (bottom; mode 2). Contoured values are principal component loadings; contour interval is 0.15 .

this pattern is most pronounced in terms of variance explained nationwide, that is, June (mode 1), July (mode 2), and August (mode 3), the magnitude of the loadings in the Southwest is relatively high. Indeed, June represents the prototype for the WO pattern. Thus the regime is more appropriately termed the Western Opposition.

Although the general form of the opposition is very persistent from month to month in the streamflow record, its specific form is quite variable seasonally. From October through December the pattern exhibits considerable stability, with a core area stretching from the coast of Washington and northern Oregon eastward into Montana. During these 3 months, a weaker core of oppositely signed loadings appears in southern California, Arizona, and parts of New Mexico. From January to May, however, the pattern varies between two configurations. One has a very localized core in coastal Washington and Oregon that appears in conjunction with a broad and relatively strong region of opposite sign across much of the arid southwest. The other has a stronger and broader pattern across several northwestern states coincident with a much weaker and less well defined oppositely signed regime in the southwest. During the summer season, the pattern achieves its most notable form with a very strong and stable pattern in the northwest along with a comparatively strong and stable opposition 
Western Opposition Pattern - March (mode 8, 4.5\%)

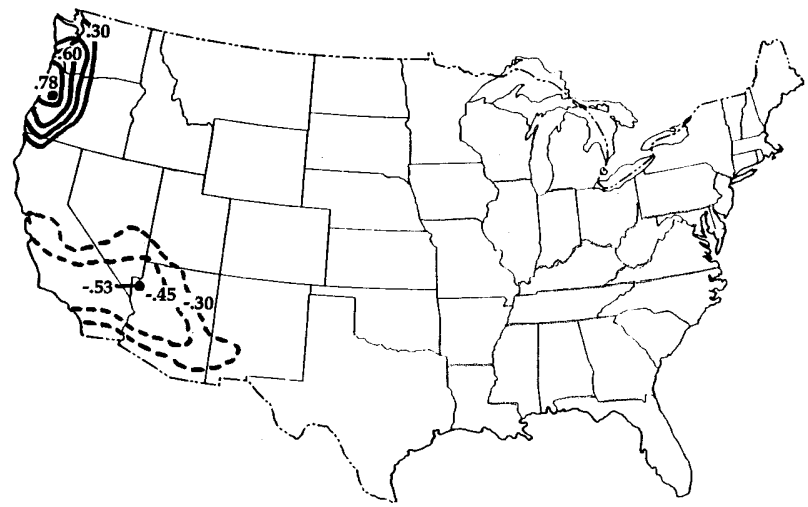

Western Opposition Pattern - June (mode 1, 9.5\%)

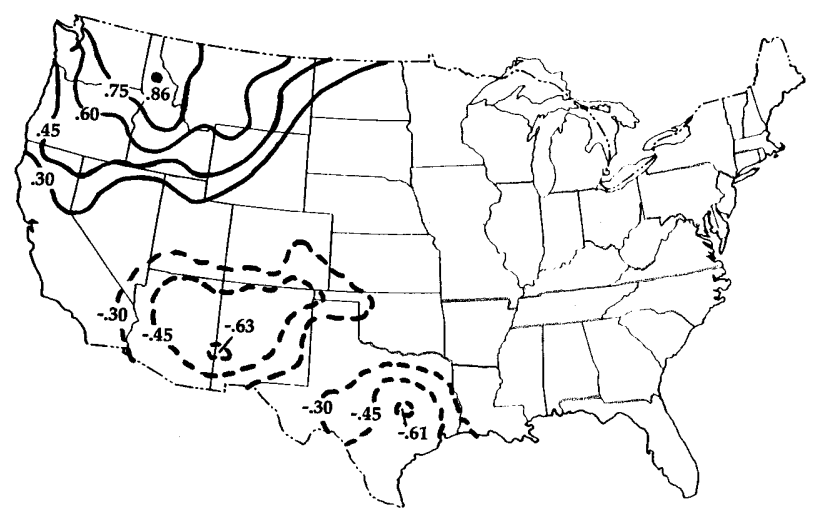

Figure 7. The Western Opposition (WO) pattern of streamflow variability in March (top; mode 8) and June (bottom; mode 1). Contoured values are principal component loadings; contour interval is 0.15 .

pattern having centers in eastern Arizona and New Mexico, as well as a secondary center in southeastern Texas.

Recent attempts to explain the WO in climatological terms have focused on relating circulation indices, such as the Southern Oscillation Index (SOI), the Pacific-North American (PNA) index, and the Central North Pacific (CNP) index (all of which are intercorrelated), with seasonal and annual streamflow anomalies. For example, Cayan and Peterson [1989] note that correlations between winter season PNA or CNP and December-August mean streamflow anomalies clearly reflect variations in the strength and mean position of the North Pacific storm track entering North America. Accordingly, one of the regions where streamflow correlates best with the PNA or CNP patterns is the Pacific northwest. However, neither of these patterns show any correlation with streamflow in the southwest.

The same authors then show that the SOI, while also positively correlated with streamflow in the northwestern United States is, more significantly, negatively correlated with streamflow in the southwestern United States. Redmond and Koch [1991] report similar regionally opposing correlations in relating annual (water year) streamflow with the SOI averaged over the preceding and overlapping June-to-November period. The differences in the regional correlation patterns of the PNA, $\mathrm{CNP}$, and SOI with streamflow in western North America
Far West Pattern -- December (mode 4, 7.1\%)

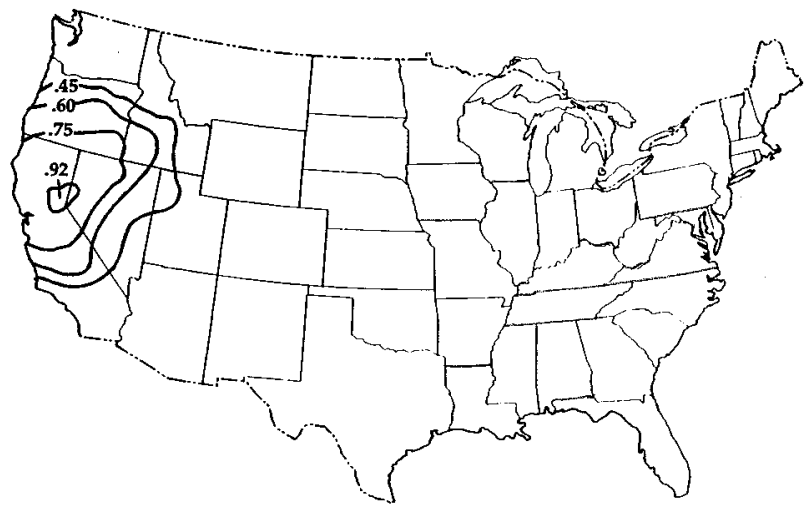

Far West Pattern -- July (mode 3, 7.9\%)

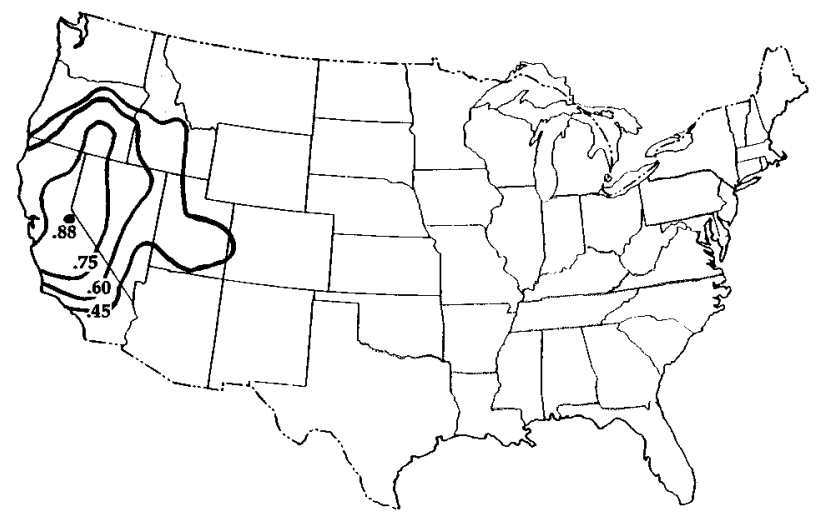

Figure 8. The Far West (FW) pattern of streamflow variability in December (top; mode 4) and July (bottom; mode 3). Contoured values are principal component loadings; contour interval is 0.15 .

illustrate the complexity of the hydroclimatic system. Although all three circulation indices are intercorrelated, they do not always occur simultaneously. For example, the PNA is observed during warm (El Niño), cold (La Niña), and transitional phases of the SOI. Conversely, a strong SOI phase can occur in the absence of a well-defined PNA. What this suggests, in terms of the appearance of the Western Opposition, is that the pattern occurs in response to a mixed-distribution of atmospheric circulation types. The concept of hydroclimatically defined mixed distributions is widely recognized, and well documented with respect to flood series [Hirschboeck, 1987; Waylen and Woo, 1982].

\section{Far West Pattern (FW)}

The final all-season regime is termed the Far West pattern. Its appearance and form are clear and well defined in all 12 months (Figure 8). Although the pattern's configuration varies considerably from month to month, it generally maintains a stable core centered on the border area of northern California and western Nevada. In some months FW appears almost entirely within the borders of California (e.g., February and April); in others it expands to include parts of the Pacific northwest (e.g., December, March, and July); at other times it stretches across the Sierra Nevada mountains into the Great Basin. Obviously, this pattern encompasses a number of dis- 
tinct physiographic and hydrologic conditions, from broad valleys and plains to high plateau and alpine. Such diversity, coupled with discharge regimes that vary from median maxima in winter, spring, and summer, probably contribute to its appearance in all months of the year.

Reference to a Far West pattern of streamflow variability is less common in the scientific literature than to the WO. Lins [1985a] defined a similar "Far West" region in his principal components analysis of mean annual streamflow for the United States. However, most recent hydroclimatological characterizations refer more generically to coherent streamflow behavior in the "western United States." Cayan and Peterson [1989, p. 375], for example, note that streamflow anomalies in the western United States "are fairly well correlated over scales of several hundred kilometers." The authors attribute this spatial correlation primarily to the strength and position of the Aleutian Low. For streams along the west coast the circulation pattern associated with positive streamflow anomalies is low pressure centered off the coast to the west or northwest, which is indicative of increased winter storms and an anomalous westerly to southwesterly wind component. For streams in the more interior regions of the west, positive streamflow anomalies are associated with a more distant positive sea level pressure (SLP) anomaly over the central North Pacific and with negative, but generally weaker, SLP anomalies locally.

\section{Southern Plains Pattern (SP)}

The first of several season-specific streamflow regimes appears in the Southern Plains (Figure 9; Table 2). SP is a cold-season pattern, first emerging in September and then persisting through April. The pattern has a core area in central to south-central Texas, although secondary centers appear in New Mexico (October, November, and April) and Oklahoma (December). In September, SP is relatively weak and of limited geographical extent. At this time it explains only $3.5 \%$ of the variance in U.S. streamflow (mode 10; Table 2). It is strongest in January, March, and April, when it explains 5.8\% (mode 5), $5.8 \%$ (mode 6 ), and $6.4 \%$ (mode 6 ) of the variance, respectively.

A distinguishing feature of the SP pattern is that it encompasses a region characterized by very persistent monthly climatic anomalies. The area underwent several years of uninterrupted drought during the early and mid 1950s [Nace and Pluhowski, 1965]. Similarly, it was engulfed in drought for 14 consecutive months during water year 1967 and early 1968 [Holmes, 1987]. Moreover, the persistence is not restricted to dry conditions, as the area associated with the SP pattern experienced above-normal streamflow for most of the winterseason months during the years 1972 to 1975 [Holmes, 1987]. It is conceivable that the SP pattern owes its cold season existence, at least in part, to the oscillating warm and cold episodes of the tropical Pacific. Ropelewski and Halpert [1987], for example, demonstrated a significant correlation between the lowindex phase of the Southern Oscillation ( $\mathrm{El} \mathrm{Niño)} \mathrm{and} \mathrm{en-}$ hanced precipitation in Texas and across the Gulf states from October in the year when high sea-surface temperatures first appear until March of the subsequent year. Significantly, they later identified a clear tendency for precipitation in the same area to average below median during the season beginning in October of the event year and ending in April of the following year during high-index phase Southern Oscillation (La Niña) events [Ropelewski and Halpert, 1989]. Thus the cold season
Southern Plains Pattern -- December (mode 7, 4.9\%)

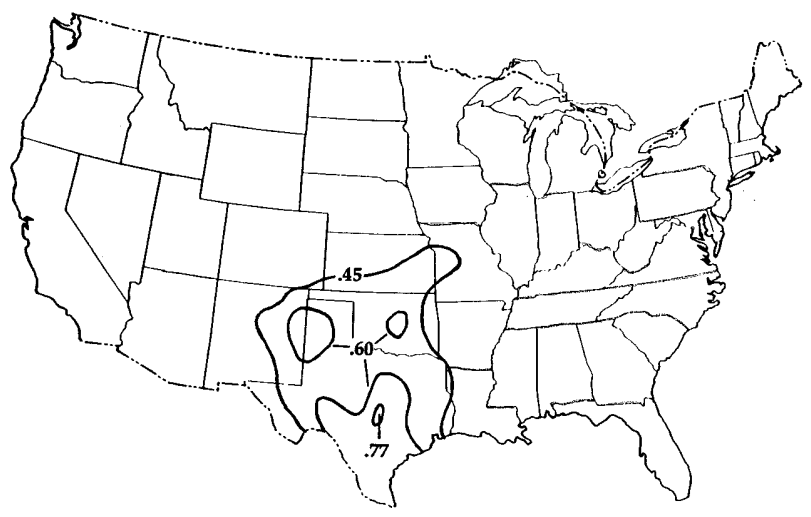

Southern Plains Pattern - March (mode 6, 5.8\%)

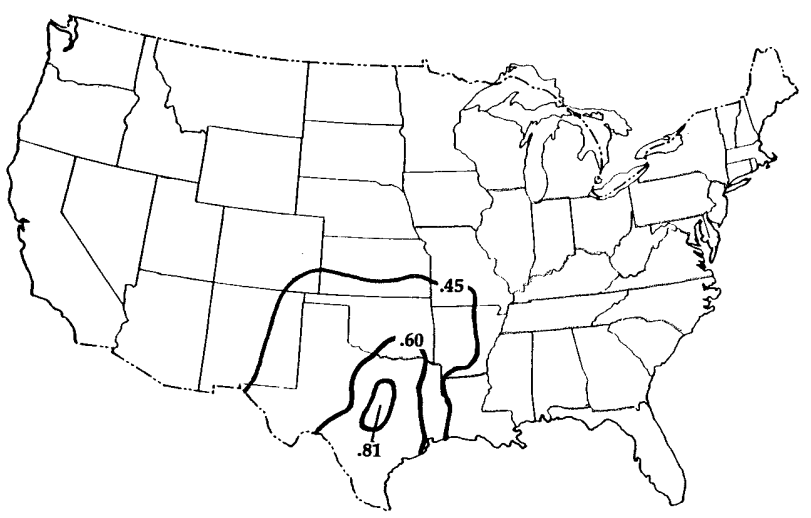

Figure 9. The Southern Plains (SP) pattern of streamflow variability in December (top; mode 7) and March (bottom; mode 6). Contoured values are principal component loadings; contour interval is 0.15 .

appearance of the Southern Plains pattern is contemporaneous with a significant climatic forcing mechanism.

\section{New England Pattern (NEW)}

A weaker and less stable cold-season pattern appears in New England (Figure 10). This regime is best defined during the 3-month period November-January, when it explains between $3.4 \%$ and $4.6 \%$ of the variance (modes 9, 9, and 6, respectively; Table 2). However, NEW is also observed in April (mode 10) and in August (mode 9). The occurrence in April comes in conjunction with the timing of the region's snowmeltgenerated maximum median monthly flow which, in general, is more than twice the median annual flow [U.S. Water Resources Council, 1978]. Its appearance in August may be associated with the more frequent occurrence of frontal storms and cyclones in this region than elsewhere in the United States at this time [Whittaker and Horn, 1984].

$\mathrm{NEW}$ is distinct from NE in that its geographical center is located in Maine rather than in New York. Its delineation as a separate but adjacent regional pattern of variation indicates that its receipt of moisture has unique characteristics, even though in many instances the same synoptic storm events may be affecting both regions. These differences could be in precipitation type (rain versus snow), precipitation intensity, and magnitude, or in storm duration. It also appears that some of 
New England Pattem - November (mode 9, 3.5\%)

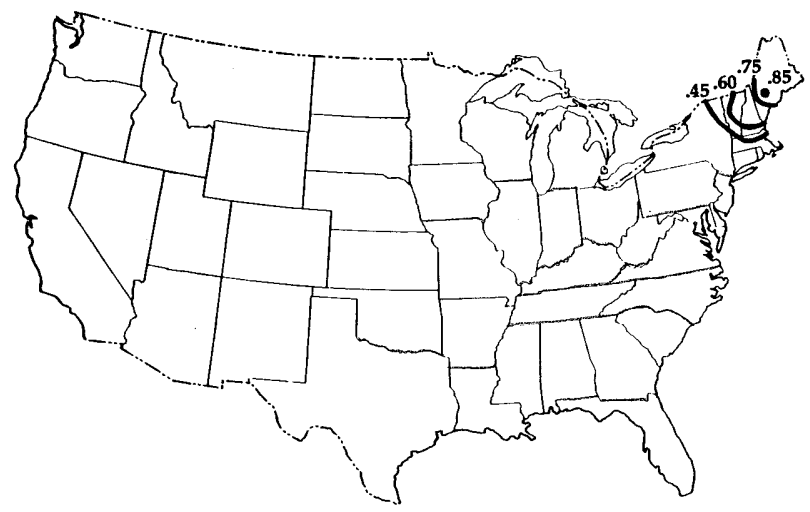

New England Pattern - January (mode 6, 4.6\%)

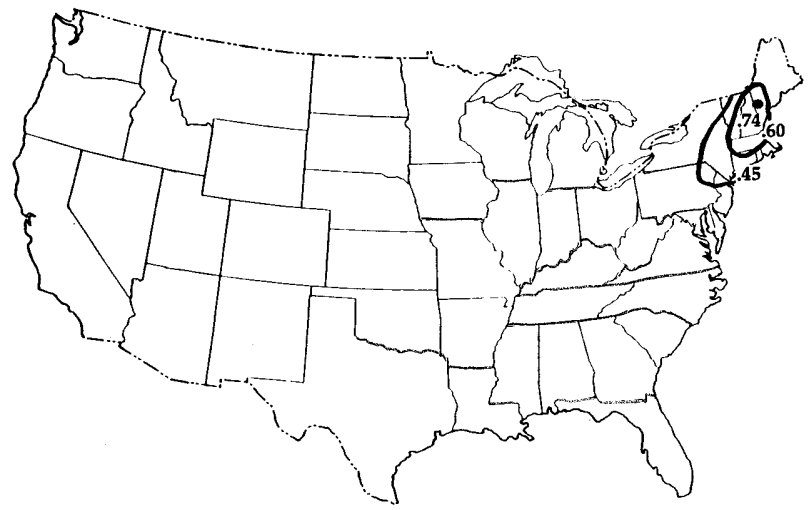

Figure 10. The New England (NEW) pattern of streamflow variability in November (top; mode 9) and January (bottom; mode 6). Contoured values are principal component loadings; contour interval is 0.15 .

variance attendant to the New England pattern is caused by storm systems that affect Maine, Vermont, New Hampshire, and Massachusetts but not the states immediately to the south and west. These are storms that track just far enough off the east coast of the United States to miss delivering significant precipitation to New York and Pennsylvania, areas at the core of the NE pattern during the winter season.

\section{Rocky Mountain Pattern (RM)}

In contrast to SP and NEW, a distinct warm-season pattern is evident in the mountainous west, primarily centered on the central and southern Rocky Mountains (Figure 11). When this Rocky Mountain (RM) pattern first appears in April, however, it has a much broader area of influence, including the northern Rockies and parts of the Sierra Nevada. The regime is observed continuously from April through July, the period dominated by snowmelt-generated runoff in the Rockies. Indeed, for most streams in the RM region, $65-85 \%$ of the mean annual streamflow occurs during the 4-month period AprilJuly [Lawrence, 1987]. RM achieves its greatest strength in its initial appearance in April (mode 2), explaining 9.1\% of the variance in nationwide streamflow (Table 2). It then becomes a much weaker pattern, occuring as mode 8 in May and July and as mode 9 in June and September. Most certainly, its
Rocky Mountain Pattern -- June (mode 9, 4.1\%)

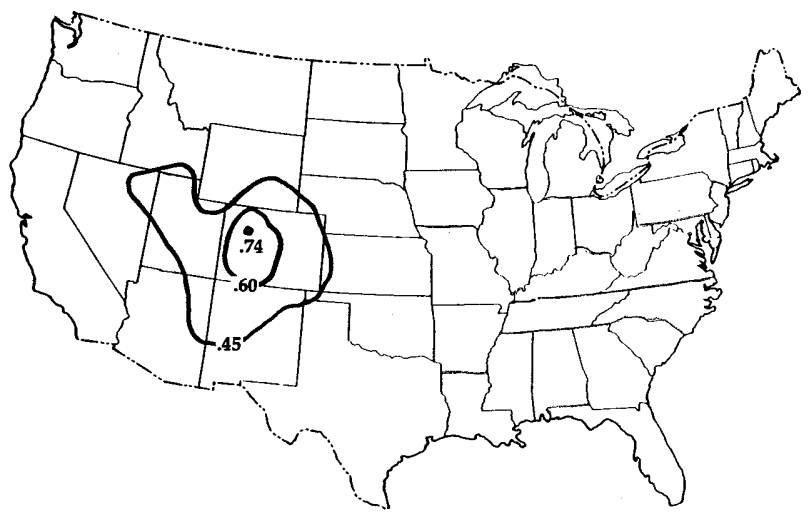

Rocky Mountain Pattern -- July (mode 8, 4.5\%)

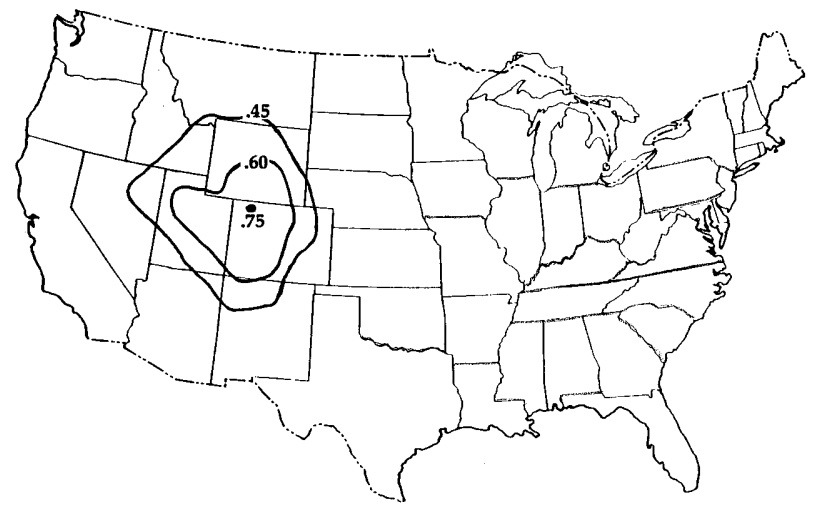

Figure 11. The Rocky Mountain (RM) pattern of streamflow variability in June (top; mode 9) and July (bottom; mode 8 ). Contoured values are principal component loadings; contour interval is 0.15 .

strong showing in April reflects the initial release of water that was stored over the winter as snow.

\section{Middle Mississippi Pattern (MM)}

A second warm season regime is tightly centered on the border area of Missouri and Arkansas, and is termed the Middle Mississippi pattern (Figure 12). This regime is observed in June (mode 8), August (mode 7), and September (mode 8), explaining a little more than $5 \%$ of the total streamflow variance in each instance (Table 2). The most notable characteristic of this streamflow pattern is that it occurs coincident with the timing of minimum median monthly flows. Analysis of gage records within the MM region indicates that in general, streamflow during the June-September period accounts for only $10-15 \%$ of the annual average. June flows mark the transition from the annual high-flow period which occurs from March to May. August and September are generally the lowest-flow months of the year.

Before leaving this section, it is instructive to return briefly to the issue of pattern bias associated with performing an RPCA on data collected from a nonuniformly distributed spatial sample. Although arguments were presented earlier to justify this approach, an additional argument can now be made on the basis of the results presented in this present section. Recall that a criticism of applying RPCA to irregularly spaced 
Middle Mississippi Pattern -- June (mode 8, 5.6\%)

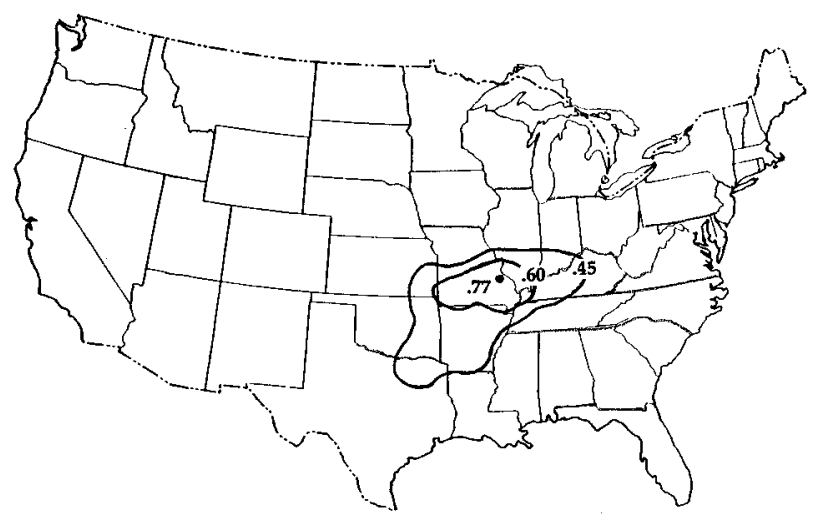

Middle Mississippi Pattern -- August (mode 7, 5.0\%)

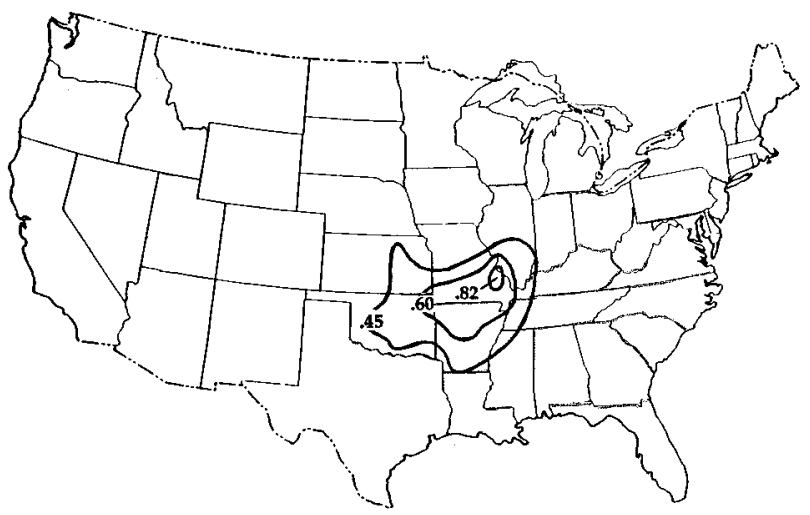

Figure 12. The Middle Mississippi (MM) pattern of streamflow variability in June (top; mode 8) and August (bottom; mode 7). Contoured values are principal component loadings; contour interval is 0.15 .

data is that component patterns will be biased toward areas having a higher density of sample points. If this is so, one would expect, on the basis of the distribution of gage sites in Figure 1, to have regional patterns centered on the IowaWisconsin-Illinois border area (Upper Mississippi region), the Appalachian Mountain segment of the mid-Atlantic region, the area in northern New Mexico, and in south Texas, as well as several other areas of locally high sample point density.

Considering the regions delineated in this analysis, there are indeed a number of areas that conform to the higher density concentrations of gages, for example, the Upper Mississippi, the Ohio Valley, and the Southern Plains. However, there are other areas such as in northern New Mexico and New Jersey where high gage density does not correspond to a unique regional streamflow regime. Moreover, if the regional regimes associated with densely gaged areas were just an artifact of the partitioning of variance explained by the RPCA, that is, regions of greater numbers of gages explain more of the total variance in streamflow, then one would expect the Upper Mississippi and Eastern/Mid-Atlantic regions to always be the first or second principal component. From a review of Table 2 it is clear that they are not. Indeed, the Upper Mississippi region varies from the first to the seventh principal component, while the Eastern/Mid-Atlantic region varies from the first to the sixth component. At the same time, areas with a much lower density of gages can explain a relatively high percentage of the variance. Such a case occurs in April when the Rocky Mountain region appears as the second principal component.

What seems clear from the analysis described herein is that regional streamflow regimes are delineated for most regions of the country where HCDN stream gages are located, without regard to the density of the gage network. Seasonal variations in principal component mode number for the delineated regions, appearance of the regions in only certain months, and the lack of unique regimes in some areas where gage clusters exist all support the argument that the streamflow patterns defined in this RPCA of irregularly spaced stream gage data reflect genuine patterns of natural variability in the hydrologic system and are not simply statistical artifacts.

\section{Conclusions and Implications}

In view of the need for a systematic characterization of the hydrologic response to climate variability, on regional-tonational and monthly-to-seasonal bases, an attempt has been made to develop a monthly hydroclimatology of regional streamflow for the United States. The analyses performed indicate clearly that U.S. streamflow is organized in coherent regional modes of variability that have distinct patterns of seasonality and persistence. Most of these regional anomaly patterns occur in all seasons of the year. A few, however, appear primarily during the cooler months or only during the warmer months. These seasonal characteristics, coupled with the contiguous spatial form of a number of the patterns (e.g., the Ohio Valley, Eastern/Mid-Atlantic, and South Atlantic/ Gulf), indicate that regional flow anomalies are linked to the seasonally varying paths of the primary and secondary storm tracks. A useful follow-up to this study would be to see if the same modes of hydrologic variability are present in 3-day or 7 -day mean discharge. Such an analysis could provide important insights on the atmospheric dynamics responsible for these regional streamflow anomalies.

A potentially notable implication of these findings relates to the delineation of water resources regions. In 1970, the U.S. Water Resources Council (WRC) defined 21 major geographic areas, or regions, for the purpose of assessing the state of water resources across the nation [U.S. Water Resources Council, 1970]. Such a regionalization was necessary because federal and state agencies, congress and its committees, river-basin commissions, and others were using incompatible criteria for names, codes, hydrographic boundaries, and river basins in treaties, compacts adjudications, and presidential executive orders. The WRC's regional delineations were based purely on geographic considerations, that is, the location of natural drainage divides. The accepted system of uniform hydrologic boundaries currently in use is a hierarchy of levels composed of 21 regions, 222 subregions, 352 accounting units, and 2150 cataloging units (Seaber et al., 1987).

Its most enduring use is in planning activities associated with land and water resources and in organizing and disseminating data. It appears to have found much less use in hydrologic research, possibly because many of the processes affecting hydrologic conditions and variability are not geographically constrained by drainage divides. A few examples from the present study highlight this point.

The Tennessee (WRC region 6) is a relatively narrow area, aligned east-west along the course of the Tennessee River. It separates the Ohio (region 5) from the South Atlantic/Gulf 
(region 3). From a hydroclimatic perspective, the Tennessee region does not have a pattern of variance distinct from the two adjacent regions. Streamflow in the western part of the region varies in conjunction with the Ohio Valley pattern of this study, particularly during the winter season. This indicates a linkage with storms that track northeastward across the central part of the country into the Great Lakes area. In the eastern half of the Tennessee region, in contrast, streamflow varies in association with the South Atlantic/Gulf pattern, primarily during the spring, summer, and autumn seasons. Thus, on a purely hydroclimatic basis, there is little rationale for a distinct Tennessee region although, admittedly, this may not be true on a political or administrative basis.

In the west, California and the Great Basin (WRC regions 18 and 16) are not hydroclimatically distinct. In general, streamflow in all but the southern quarter of California varies with streamflow in the Great Basin in a systematic pattern defined herein as the Far West. Southern California more commonly behaves hydrologically opposite the Pacific northwest, in conformance with the Western Opposition pattern. Thus the WRC regions are poorly delineated in terms of representing coherent regional patterns of streamflow covariability.

Indeed, none of the $18 \mathrm{WRC}$ regions within the conterminous United States conforms closely to any single pattern of regional streamflow variability defined in the present investigation. On the other hand, except for the Missouri (region 10), Souris-Red-Rainy (region 9), Great Lakes (region 4), Tennessee (region 6), and the Arkansas-White-Red (region 11), the other WRC regions exhibit some broad geographic similarities with at least one of the hydroclimatically determined areas.

An implication of this finding is that the utility of the WRC regions, for planning, hydrologic characterization, and many types of research, could be improved by modifying the current regional boundaries to incorporate the spatial coherence inherent in the hydroclimatic regimes of this investigation. Such a change would also provide the WRC regions a more scientifically defensible basis. In addition, since conformance to political boundaries was not intrinsically part of the WRC regionalization, a realignment of the current boundaries should not pose significant jurisdictional obstacles.

\section{References}

Barnston, A. G., and R. E. Livezey, Classification, seasonality and persistence of low-frequency atmospheric circulation patterns, Mon Weather Rev., 115, 1083-1126, 1987.

Bartlein, P. J., Streamflow anomaly patterns in the U.S.A. and Southern Canada-1951-1970, J. Hydrol., 57, 49-63, 1982.

Beard, L. R., Flood flow frequency techniques, Tech. Rep. 119, 28 pp., Cent. for Res. in Water Resour., Univ. of Tex., Austin, 1974.

Brinkmann, W. A. R., Sea-level pressure patterns over eastern North America, Mon. Weather Rev., 109, 1305-1314, 1981.

Buell, C. E., Integral equation representation for factor analysis, $J$. Atmos. Sci., 28, 1502-1505, 1971.

Busby, M. W., Yearly variations in runoff for the conterminous United States, 1931-60, U.S. Geol. Surv. Water Supply Pap. 1669-S, 49 pp., 1963.

Cayan, D. R., and D. H. Peterson, The influence of North Pacific atmospheric circulation on streamflow in the west, in Aspects of Climate Variability in the Pacific and the Western Americas, Geophys. Monogr. Ser., vol. 55, edited by D. H. Peterson, pp. 365-374, AGU, Washington, D. C., 1989

Dolan, R., H. Lins, and B. Hayden, Mid-Atlantic coastal storms, $J$. Coastal Res., 4, 417-433, 1988.

Gleick, P. H., Regional hydrologic consequences of increases in atmospheric $\mathrm{CO}_{2}$ and other trace gases, Clim. Change, 10, 137-161, 1987.
Guetter, A. K., and K. P. Georgakakos, River outflow of the conterminous United States, 1939-1988, Bull. Am. Meteorol. Soc., 74, 1873-1891, 1993.

Hay, L. E., G. J. McCabe, D. M. Wolock, and M. A. Ayers, Use of weather-type analysis to disaggregate general circulation model predictions, J. Geophys. Res., 97, 2781-2790, 1992.

Hayden, B. P., Secular variation in Atlantic coast extratropical cyclones, Mon. Weather Rev., 109, 159-167, 1981.

Hirschboeck, K. K., Hydroclimatically-defined mixed distributions in partial duration flood series, in Hydrologic Frequency Modeling, edited by V. P. Singh, pp. 199-212, D. Reidel, Norwell, Mass., 1987.

Holmes, S. L., Monthly streamflow and ground-water conditions in the United States and Southern Canada, water years 1945-85, U.S. Geol. Surv. Water Supply Pap. 2314, 250 pp., 1987.

Horel, J. D., A rotated principal component analysis of the interannual variability of the Northern Hemisphere $500 \mathrm{mb}$ height field, Mon. Weather Rev., 109, 2080-2092, 1981.

Horel, J. D., Complex principal component analysis: Theory and examples, J. Clim. Appl. Meteorol., 3, 1660-1673, 1984.

Karl, T. R., and A. J. Koscielny, Drought in the United States: 18951981, J. Clim., 2, 313-329, 1982.

Karl, T. R., A. J. Koscielny, and H. F. Diaz, Potential errors in the application of principal component (eigenvector) analysis to geophysical data, J. Appl. Meteorol., 21, 1183-1186, 1982.

Langbein, W. B., and J. R. Slack, Yearly variations in runoff and frequency of dry years for the conterminous United States, 1911-79, U.S. Geol. Surv. Open File Rep. 82-751, 85 pp., 1982.

Lawrence, C. L., Streamflow characteristics at hydrologic bench-mark stations, U.S. Geol. Surv. Circ. 941, 123 pp., 1987.

Lins, H. F., Streamflow variability in the United States, 1931-78, J. Clim. Appl. Meteorol., 24, 463-471, 1985a.

Lins, H. F., Interannual streamflow variability in the United States based on principal components, Water Resources Res., 21, 691-701, $1985 b$.

Lins, H.F., Recent patterns of sulfate variability in pristine streams, Atmos. Environ., 20, 367-375, 1986.

Meko, D. M., and C. W. Stockton, Secular variation in streamflow in the western United States, J. Clim. Appl. Meteorol., 23, 889-897, 1984.

Nace, R. L., and Pluhowski, Drought of the 1950's with special reference to the midcontinent, U.S. Geol. Surv. Water Supply Pap. 1804, 88 pp., 1965.

Namias, J., Northern hemisphere seasonal $700 \mathrm{mb}$ height and anomaly charts, 1947-1978, and associated North Pacific sea surface temperature anomalies, Calif. Coop. Oceanic Fish. Invest. Atlas 27, 275 pp., 1979.

Overland, J. E., and R. W. Preisendorfer, A significance test for principal components applied to a cyclone climatology, Mon. Weather Rev., 110, 1-4, 1982.

Preisendorfer, R. W., Principal component analysis in meteorology and oceanography, in Developments in Atmospheric Science, vol. 17, 425 pp., Elsevier, New York, 1988.

Preisendorfer, R. W., and T. P. Barnett, Significance tests for empirical orthogonal functions, paper presented at Fifth Conference on Probability and Statistics in Atmospheric Sciences, Am. Meteorol. Soc., Las Vegas, Nev., 1977.

Preisendorfer, R. W., F. W. Zwiers, and T. P. Barnett, Foundations of principal component selection rules, SIO Ref. Ser. 81-4, 192 pp., Scripps Inst. of Oceanogr., 1981.

Redmond, K. T., and R. W. Koch, Surface climate and streamflow variability in the western United States and their relationship to large-scale circulation indices, Water Resour. Res., 27, 2381-2399, 1991

Richman, M. B., Rotation of principal components, J. Clim., 6, 293335, 1986.

Richman, M. B., and P. J. Lamb, Climatic pattern analysis of 3- and 7-day summer rainfall in the central United States: Some methodological considerations and a regionalization, J. Clim. Appl. Meteorol., 24, 1325-1343, 1985.

Ropelewski, C. F., and M. S. Halpert, Global and regional scale precipitation associated with El Niño/Southern Oscillation, Mon. Weather Rev., 115, 1606-1626, 1987.

Ropelewski, C. F., and M. S. Halpert, Precipitation patterns associated with the high index phase of the Southern Oscillation, J. Clim., 2, 268-284, 1989. 
Seaber, P. R., F. P. Kapinos, and G. L. Knapp, Hydrologic unit maps, U.S. Geol. Surv. Water Supply Pap. 2294, 63 pp., 1987.

Slack, J. R., and J. M. Landwehr, Hydro-Climatic Data Network (HCDN): A U.S. Geological Survey streamflow data set for the United States for the study of climate variations, 1874-1988, U.S. Geol. Surv. Open File Rep. 92-129, 193 pp., 1992.

Slack, J. R., A. M. Lumb, and J. M. Landwehr, Hydro-Climatic Data Network (HCDN) streamflow data set, 1874-1988, U.S. Geol. Surv. Water Resour. Invest. Rep. 93-4076, 1993.

Thomas, W. O., and S. A. Olson, Regional analysis of minimum streamflow, paper presented at 12th Conference on Probability and Statistics in Atmospheric Sciences, Am. Meteorol. Soc., Toronto, 1992.

Thurstone, L. L., Multiple Factor Analysis, 535 pp., Univ. of Chicago Press, Chicago, Ill., 1947.

U.S. Water Resources Council, Water Resources Regions and Subregions for the National Assessment of Water and Related Land Resources, 188 pp., Washington, D. C., 1970.

U.S. Water Resources Council, The Nation's Water Resources 19752000, Second National Assessment by the U.S. Water Resources
Council, vol. 3, Analytical Data, Appendix V, Streamflow Conditions, 276 pp., Washington, D. C., 1978.

Walsh, J. E., and A. Mostek, A quantitative analysis of meteorological anomaly patterns over the United States, 1900-1977, Mon. Weather Rev., 108, 615-630, 1980.

Waylen, P., and M.-K. Woo, Prediction of annual floods generated by mixed processes, Water Resour. Res., 18, 1283-1286, 1982.

Whittaker, L. M., and L. H. Horn, Northern hemisphere extratropical cyclone activity for four mid-season months, J. Clim., 4, 297-310, 1984.

Zishka, K. M., and P. J. Smith, The climatology of cyclones and anticyclones over North America and surrounding ocean environs for January and July, 1950-1977, Mon. Weather Rev., 108, 387-401, 1980.

H. F. Lins, USGS, 415 National Center, Reston, VA 20192. (e-mail: hlins@usgs.gov)

(Received November 5, 1996; revised February 14, 1997;

accepted February 24, 1997.) 